Arq. Bras. Med. Vet. Zootec., v.59, n.1, p.41-48, 2007

\title{
Curvas ângulo-tempo das articulações dos eqüinos marchadores
}

\author{
[Joint angle-time curves of Brazilian gaited horses] \\ A.M. Procópio ${ }^{1}$, J.A.G. Bergmann ${ }^{2}$, H.J. Menzel ${ }^{3}$, M. S. Brêtas ${ }^{1}$, J.Herr ${ }^{4}$, P. Fantini ${ }^{5}$ \\ ${ }^{1}$ Aluno de pós-graduação - EV-UFMG - Belo Horizonte, MG \\ ${ }^{2}$ Escola de Veterinária - UFMG \\ Caixa Postal 567 \\ 30123-970 - Belo Horizonte, MG \\ ${ }^{3}$ Escola de Educação Física - UFMG - Belo Horizonte, MG \\ ${ }^{4}$ Aluna de pós-graduação - EEF-UFMG - Belo Horizonte, MG \\ ${ }^{5}$ Aluna de graduação - EV-UFMG - Belo Horizonte, MG
}

\begin{abstract}
RESUMO
Gráficos com demonstração das curvas ângulo-tempo das articulações dos membros dos eqüinos foram avaliados por meio da análise de imagens digitalizadas tomadas de 10 cavalos e 13 éguas da raça Mangalarga Marchador. Foram utilizados marcadores reflexivos adesivos colocados em 19 pontos articulares dos eqüinos, procedendo-se à filmagem com freqüência de 250 quadros por segundo e utilizando-se o aplicativo Simi-motion 3D 6.0 para digitalização e análise das imagens. A utilização dos marcadores reflexivos adesivos constituiu boa metodologia para análise dos movimentos dos segmentos ósseos dos eqüinos. Os resultados observados indicam haver, durante a locomoção dos eqüinos marchadores brasileiros, comportamento similar das articulações quando comparados com eqüinos de sela europeus, apresentando mesmo padrão das curvas de ângulo-tempo e não havendo grandes diferenças entre os pontos máximos de flexão e extensão.
\end{abstract}

Palavras-chave: eqüino, locomoção, ângulos

\begin{abstract}
Images of 10 horses and 13 mares of Mangalarga Marchador breed were taken and digitalized to analyze the joint angle-time curves. Reflexives and adhesives markers were glued on 19 articulations points of the hindlimbs and forelimbs of the horses. The images were taken at 250 frames per second and the digitalization and analysis were made using a Simi-motion $3 D 6.0$ software. The results demonstrated that the methodology using reflexives and adhesives markers was efficient to make analyses of the bone segment movements of the horses. This study concluded that the Brazilian gaited horses have a similar angle-joint curve as the European warmblood horses and there are no great differences of the maximum extension and flexion points.
\end{abstract}

Keywords: horse, locomotion, angles

\section{INTRODUÇ̃̃O}

Os eqüinos possuem variadas finalidades, sendo que, para cada uma delas, são necessários animais de tipos variados, ou seja, com diferentes e específicas características relacionadas à conformação, à aptidão, ao temperamento, ao treinamento e ao desempenho (Leach, 1983). Segundo Barrey (2001), o aparelho locomotor é um complexo sistema incluindo músculos, segmentos ósseos e articulações, que são controlados pelo sistema

Recebido em 13 de agosto de 2004

Aceito em 22 de novembro de 2006

E-mail: procopioam@yahoo.com.br 
nervoso central, produzindo a locomoção bem coordenada. Do ponto de vista da biomecânica, a locomoção do eqüino envolve movimentos de todo o corpo e de segmentos dos membros em um ritmo e padrões automáticos que definem os vários andamentos, porque a locomoção quadrupedal permite várias combinações de coordenação entre os membros.

Segundo Meershoek e Van den Bogert (2001), a coordenação entre a movimentação de cada membro e de seus segmentos auxilia no entendimento das variações existentes entre os diversos andamentos. Durante cada passada, os membros anteriores e posteriores atuam de forma a absorver impacto, vencer os efeitos da gravidade e proporcionar a propulsão, promovendo a progressão do corpo do animal. Tudo isto é obtido pela alternância entre as fases de apoio e de suspensão. Durante a fase de apoio, os membros pressionam o solo para criar a força necessária para suportar e dar propulsão à massa corpórea e durante a fase de suspensão, os membros elevam-se, avançam movimentando-se para se preparar para a próxima fase de apoio. Back et al.(1995), observaram que, embora os segmentos distais dos anteriores e posteriores sejam anatomicamente similares, eles possuem diferentes ângulos, velocidades e acelerações no início da fase de apoio. No momento do impacto, o metacarpo tem um ângulo bem maior que o metatarso, embora os ângulos do boleto sejam similares nos membros anteriores e posteriores (Clayton, 1994; Back et al.,1995). Aparentemente, a cinemática do passo e do trote é similar em termos dos padrões de coordenação intramembros, diferenciando-se quanto à distância de apoio e à duração da suspensão pelo fato de o trote ser mais rápido, existindo uma surpreendente diferença na extensão dos boletos entre o passo e o trote (Back et al., 1996). As similaridades podem refletir a influência da conformação na cinemática (Back et al.,1997).

Lage (2001) realizou estudo com a filmagem de 169 animais adultos da raça Mangalarga Marchador com tomada de medidas lineares e angulares, concluindo-se haver correlação positiva entre os quesitos que caracterizam e qualificam a marcha com o comprimento da escápula, comprimento do úmero e com a qualidade dos aprumos.
O presente trabalho tem como objetivo utilizar a cinematografia, para, a partir das imagens digitalizadas, apresentar a variação das medidas angulares dos eqüinos marchadores brasileiros durante a sua locomoção, por meio das curvas de ângulo-tempo, correlacionando-as com a fase de locomoção do animal e comparando-as com as dos cavalos de sela europeus.

\section{MATERIAL E MÉTODOS}

Os animais utilizados no estudo participaram da XXII Exposição Nacional do Cavalo Mangalarga Marchador, ocorrida entre os dias 22 e 26 de julho de 2003. Foram filmados 38 animais, sendo 10 cavalos, 13 éguas, sete potras e oito potros. Para a análise das imagens, definiu-se utilizar apenas animais adultos, campeões ou reservados campeões de andamento na exposição ou os grandes campeões da raça em exposições nacionais anteriores. Foi escolhido o Parque de Exposições Bolivar de Andrade, localizado em Belo Horizonte, Minas Gerais, por possuir todos os requisitos técnicos: piso totalmente plano, firme e não escorregadio; área coberta com $225 \mathrm{~m}^{2}$, sendo 15 metros de comprimento por 15 metros de largura, com área adjacente para a locomoção dos animais antes da entrada e após a saída da pista de filmagem; condição para a instalação de iluminação controlada, distribuída estrategicamente por seis holofotes de 500 watts cada; plano de filmagem, com fundo homogêneo; pista demarcada com $80 \mathrm{~cm}$ de largura; rede elétrica com tomadas de 220 e 110 volts; disponibilidade de animais participantes das exposições; isolamento do público.

Para a realização das filmagens, foram utilizados os seguintes equipamentos: câmera Red Lake Motionscope PCI 500, conectada ao computador com velocidade de filmagem de 250 quadros por segundo (Red Lake, 2004); programa Simi Motion 3D, versão 6.0 (Simi, 2004)

Antes das filmagens, todos os cavaleiros, montando seus respectivos animais, foram previamente orientados e treinados, realizando-se passagens experimentais em linha reta na pista demarcada, sempre da direita para a esquerda ao passo e em marcha para a ambientação dos animais ao local até que estes estivessem considerados aptos para a filmagem. A filmadora foi colocada em tripé posicionada a 14 metros perpendicularmente ao plano de filmagem, de 
forma que este plano apresentasse cerca de 7 metros no ponto central da pista, proporcionando tempo suficiente para que o animal fosse filmado com seu andamento natural, com espaço para a redução da velocidade pós-filmagem, possibilitando a captura de pelo menos uma passada completa. Os conjuntos foram mantidos com os equipamentos e as condições idênticas àquelas de quando foram avaliados para a premiação em pista. O objetivo principal foi o de analisar as características de andamento dos conjuntos ganhadores.

As imagens foram digitalizadas utilizando-se o programa Simi-Motion 3D, 6.0 (Simi, 2004) empregando-se a metodologia de análise dos ângulos por meio de imagens conforme sugeridas por Mota (1999) e Hunt et al. (1999). Os ângulos analisados foram: inclinação da escápula com a horizontal, inclinação do braço com a horizontal, ângulo escapuloumeral, ângulo úmero-radial, ângulo do carpo, ângulo coxo-femoral, ângulo femorotibiopatelar, ângulo tibiotarsicometatársico.

Para a digitalização das imagens e análise das angulações dos animais, foram fixados, nos pontos articulares do lado esquerdo do animal, 19 marcadores reflexivos adesivos com 5 centímetros de diâmetro, confeccionados a partir de material utilizado para a sinalização de placas de trânsito (Fig. 1) conforme descrição a seguir.

Na cabeça, M1 - ponto intermediário entre a rima labial e a crista facial e M2 - porção cranial da face lateral da asa do atlas; no pescoço, M3 - borda cranial do terço médio do músculo supra-espinhoso; nos membros anteriores, M4 - porção dorsal superior da espinha da escápula, M5 - área central da articulação escapuloumeral, M6 - tuberosidade radial do rádio logo abaixo da cavidade glenóidea , M7 - terço médio da articulação cárpica, rádiocárpica-matacárpica, M8 - terço médio da articulação metecarpofalangeana do membro anterior esquerdo, M9 - articulação interfalangeana proximal do membro anterior esquerdo, M10 marcador em semicírculo na face lateral do casco do membro anterior esquerdo, em contato com a ferradura ou solo, M11 - marcador em semicírculo na face medial do casco do membro anterior direito, em contato com a ferradura ou solo; nos membros posteriores, M12 - face cranial lateral da tuberosidade ilíaca, tubérculo coxal, M13 - ponto de inserção do fêmur ao acetábulo, trocânter maior, M14 - epicôndilo lateral do fêmur, M15 - terço médio na articulação társica, tíbiotarsicametatársica, M16 - terço médio da articulação metecarpofalangeana do membro posterior esquerdo, M17 - articulação interfalangeana proximal do membro posterior esquerdo, M18 - marcador em semicírculo na face lateral do casco do membro posterior esquerdo, em contato com a ferradura ou solo, e M19 - marcador em semicírculo na face medial do casco do membro posterior direito, em contato com a ferradura ou o solo.

\section{RESULTADOS E DISCUSSÃO}

Durante as filmagens, ficou evidenciada a funcionalidade da utilização dos marcadores, observando ser necessária alta precisão na sua colocação nos pontos articulares. Devido ao desconhecimento do grau de interferência do deslocamento da pele dos animais (Van Weeren et al., 1988; 1992) e a possíveis ruídos na digitalização e fixação de marcadores, evitou-se a utilização dos valores de ângulos mensurados e optou-se por dar enfoque maior às curvas ângulotempo que, juntamente com a determinação de pontos máximos e mínimos das angulações em relação à fase da passada, possibilitou a obtenção de resultados muito próximos aos observados na literatura.

A análise da inclinação da escápula com a horizontal (Fig. 2) mostra uma forma sinusoidal, conforme descrita por Back (2001). O ponto de inclinação máximo da espádua ocorreu no final da fase de apoio do membro anterior, enquanto a inclinação mínima se deu no momento imediatamente antes do seu apoio.

A maior inclinação do úmero se deu ao final da fase de elevação do membro anterior, e a menor inclinação ocorreu no momento antes do seu apoio (Fig. 3).

Para a articulação escapuloumeral, a extensão máxima ocorreu no instante imediatamente anterior ao apoio do casco ao solo, enquanto a máxima flexão ocorreu após elevação e avanço, imediatamente antes da descida do membro anterior para tocar o solo (Fig 4). Segundo Back (2001), as curvas ângulo-tempo da escápula antes e após a correção para o deslocamento da pele são similares, exceto para a inflexão na curva na metade da fase de suspensão antes da correção, quando esse ponto parece representar o momento máximo de protração após a correção. Segundo o autor, o pico de flexão antes e após a correção para deslocamento da pele é bastante visível, não ocorrendo o mesmo em outras fases. 
Para o ângulo úmero radial, observou-se que o valor máximo situava-se no momento final de apoio do membro anterior, enquanto o valor mínimo ocorreu na metade da fase de avanço do membro anterior (Fig. 5). Segundo Back (2001), essa articulação durante a fase de suspensão passa por um ciclo de flexão. As amplitudes máximas de flexão e extensão do parecem não ser influenciadas pelo deslocamento da pele, mas os picos de flexão ocorrem somente antes da fase de suspensão. A ação dos extensores suaviza a flexão articular e, então, reverte a direção do movimento.

No carpo observou-se que a extensão máxima ocorreu na metade da fase de apoio do membro anterior, quando ele permaneceu quase perpendicular ao solo, chegando próximo a 180 graus. A flexão máxima se deu logo após a fase de elevação e início do avanço do membro anterior (Fig. 6). As representações foram muito semelhantes às descritas por Back (2001), que observou ainda que a correção para deslocamento da pele não alterou a curva significantemente.

A partir da Fig. 7, observou-se que o ponto de maior extensão da articulação coxo-femoral ocorreu no momento final da fase de apoio do membro posterior, enquanto na fase final do avanço do membro posterior e no momento que antecedeu a descida do casco, observou-se a maior flexão. A comparação entre as Fig. 6 e 7 revela que as angulações do carpo e coxofemoral apresentam valores máximos em tempos muito próximos, o que deve ser objeto de estudo posterior. Back (2001) observou que, na articulação coxo-femoral, após correção para o deslocamento da pele, o padrão foi bastante modificado, mas os limites de movimentação foram tão altos quanto sem correção.

$\mathrm{Na}$ angulação da articulação femorotibiopatelar (Fig. 8), pôde-se observar interferência do deslocamento da pele sobre o marcador colocado na patela, assim, a forma da curva deve ser analisada com cautela. Back (2001), em seu estudo, afirmou que a correção para o deslocamento da pele revelava que a máxima flexão da patela ocorria um pouco após e mais pronunciadamente do que no presente estudo. A Fig. 8 evidencia que o valor máximo ocorreu antes do apoio do membro posterior, e o valor mínimo após a elevação máxima do membro posterior, no instante em que antecedeu seu avanço.

Para a articulação tibiotarsicametatársica, a extensão máxima se deu ao final da fase de apoio do membro posterior, enquanto a máxima flexão ocorreu após a fase de elevação do membro posterior (Fig. 9).

\section{CONCLUSÕES}

A utilização de marcadores adesivos reflexivos, com cinco centímetros de diâmetro, nos pontos articulares dos eqüinos, constituiu-se em procedimento adequado para a posterior digitalização das imagens, permitindo nítida visualização dos movimentos dos segmentos ósseos e, conseqüentemente, a quantificação das medidas angulares. As curvas ângulo-tempo dos eqüinos marchadores apresentaram padrão semelhante ao de eqüinos de sela europeus, sugerindo não haver diferenças acentuadas no tocante à coordenação intramembro desses animais. 


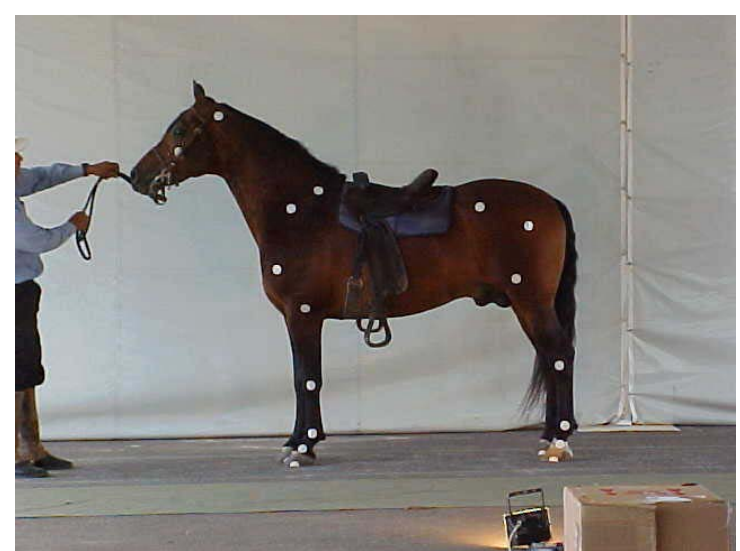

Figura 1. Marcadores adesivos reflexivos nos pontos articulares de eqüino.
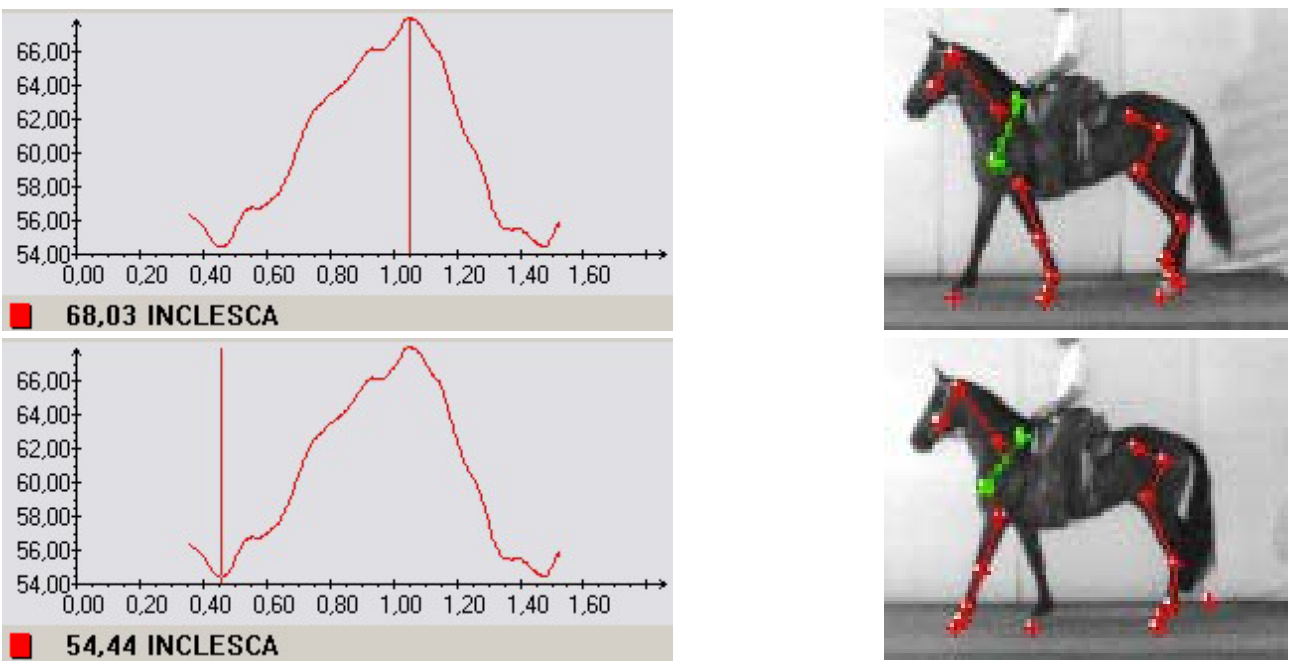

Figura 2. Curvas ângulo-tempo da inclinação da escápula com a horizontal (em verde).
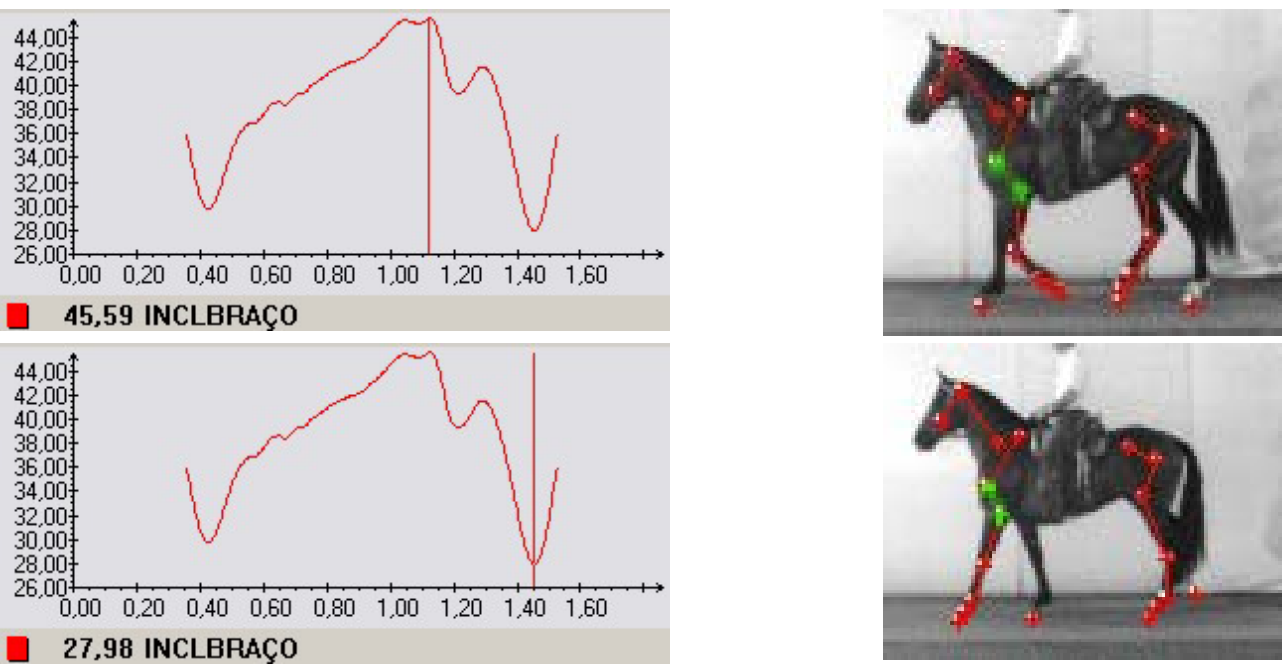

Figura 3. Curvas ângulo-tempo da inclinação do úmero com a horizontal (em verde). 


\section{Procópio et al.}
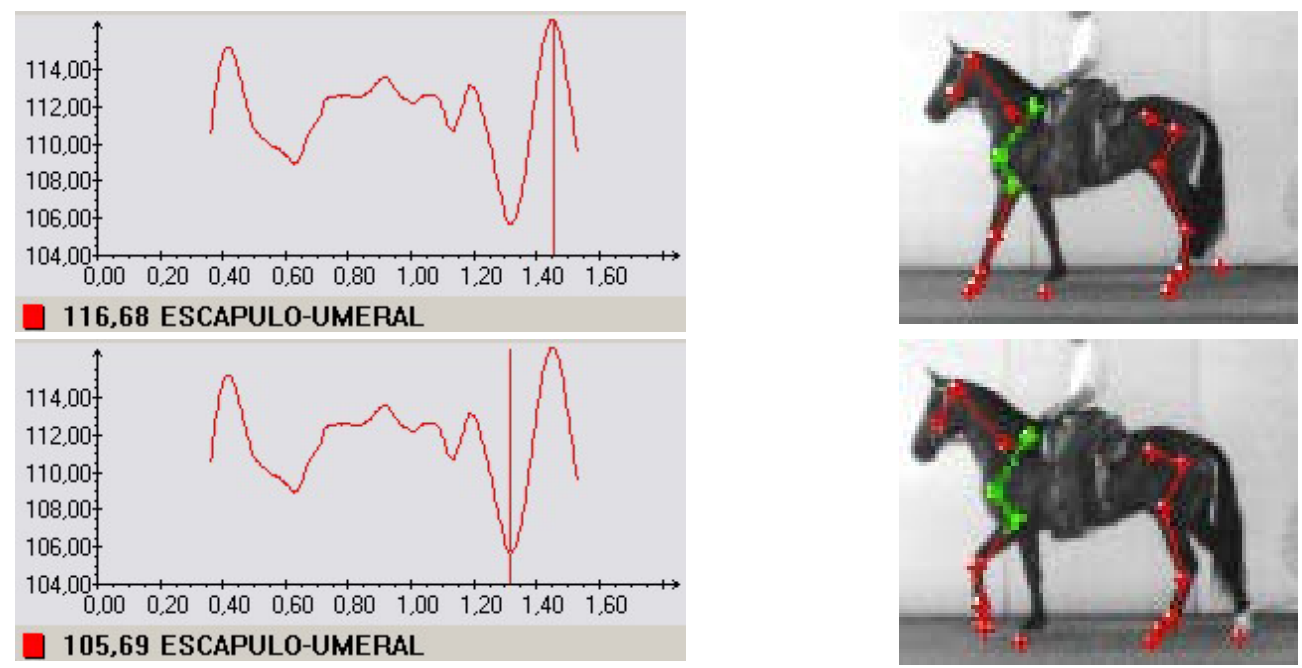

Figura 4. Curvas ângulo-tempo e pontos de máximo e mínimo do ângulo escápulo-umeral (em verde).
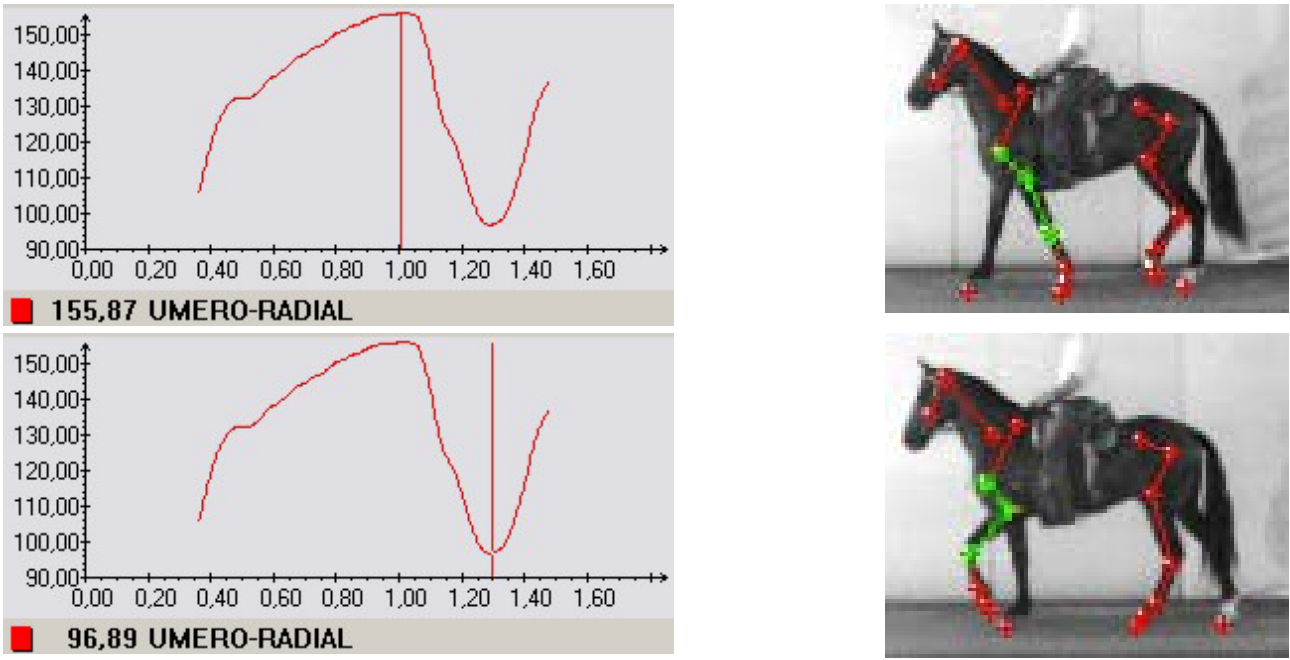

Figura 5. Curvas ângulo-tempo e pontos de máximo e mínimo do ângulo úmero-radial (em verde).
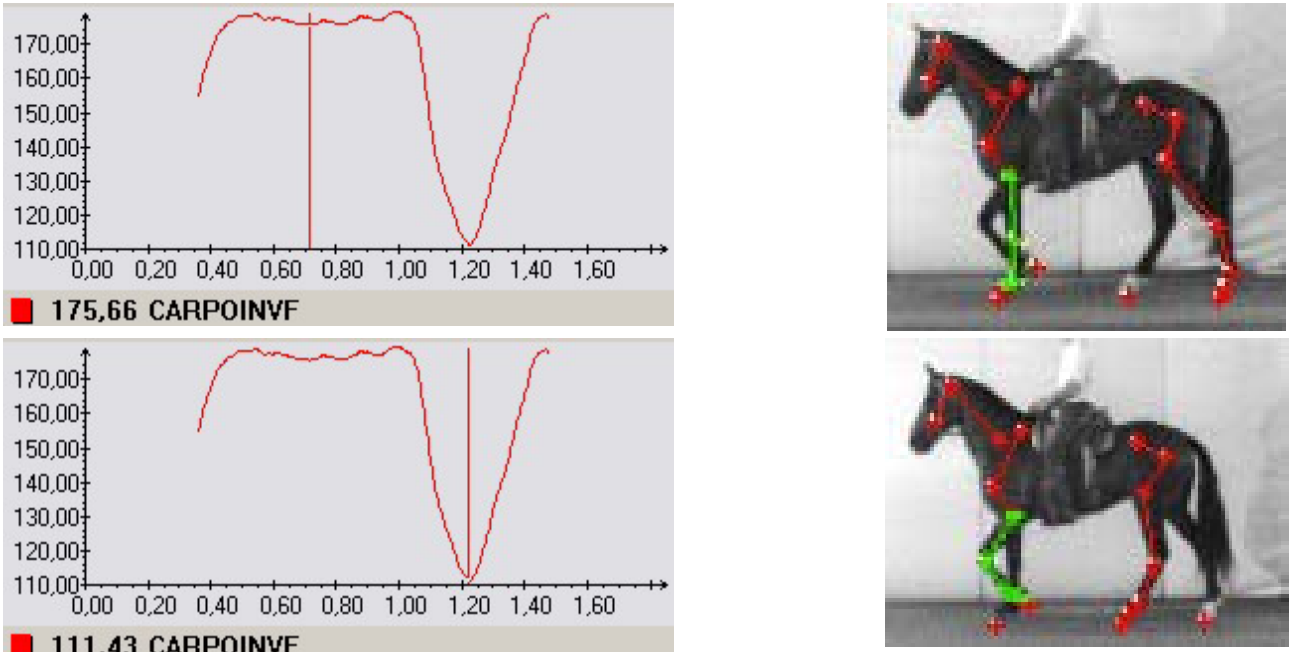

Figura 6. Curvas ângulo-tempo e pontos de máximo e de mínimo do ângulo do carpo (em verde). 

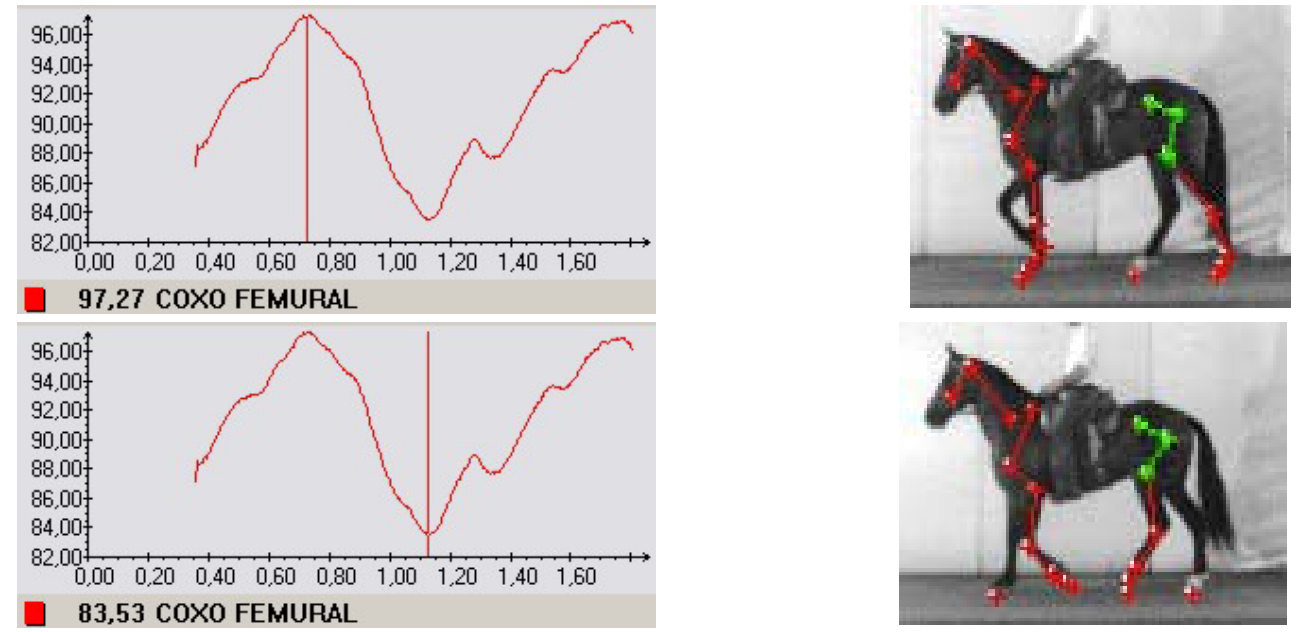

Figura 7. Curvas ângulo-tempo e pontos de máximo e mínimo do ângulo coxofemoral (em verde).
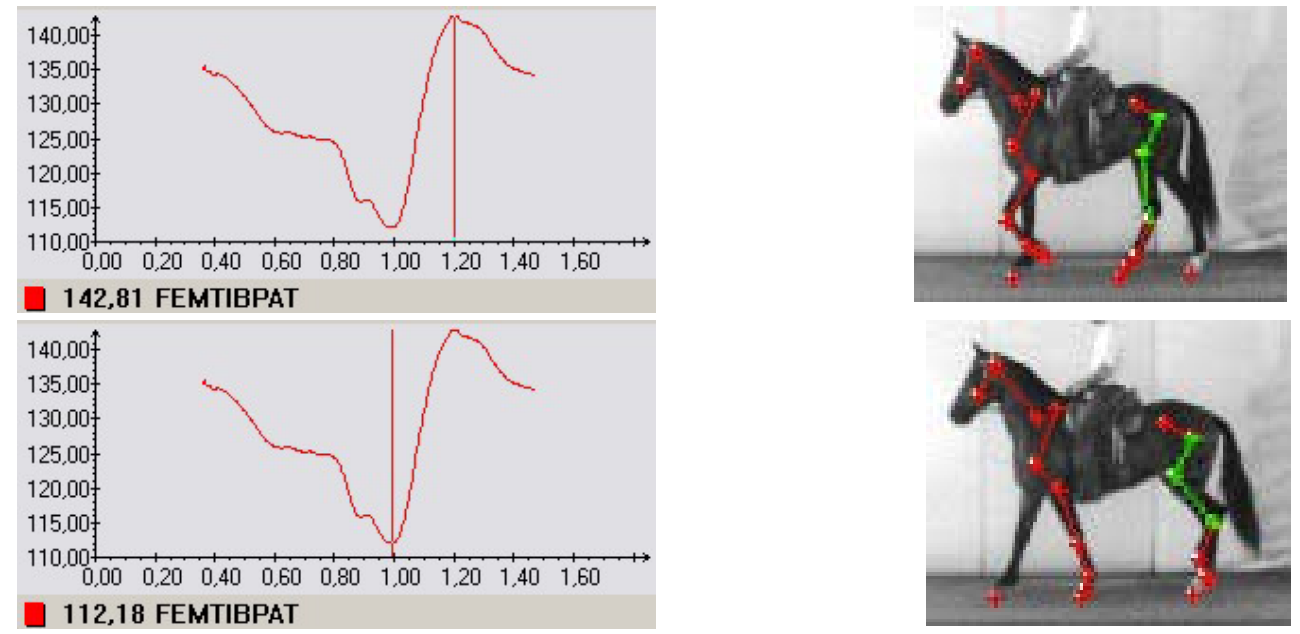

Figura 8. Curvas ângulo-tempo e pontos de máximo e mínimo do ângulo femurotibiopatelar (em verde).
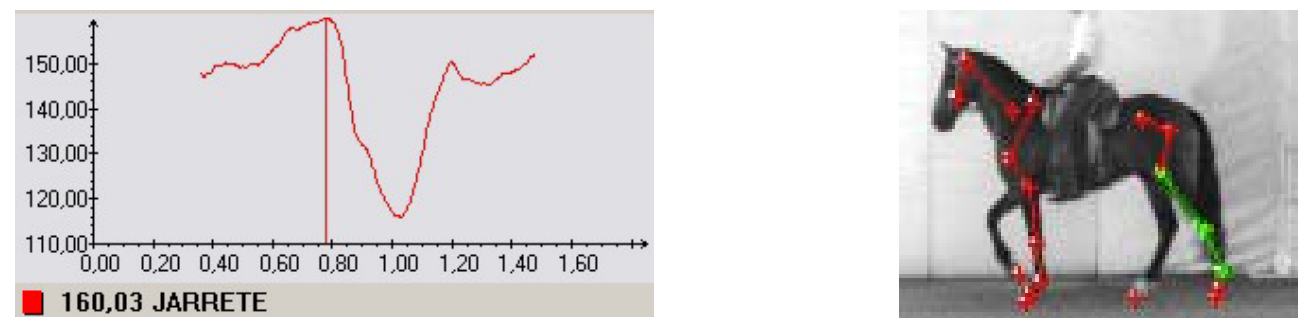

160,03 JARRETE
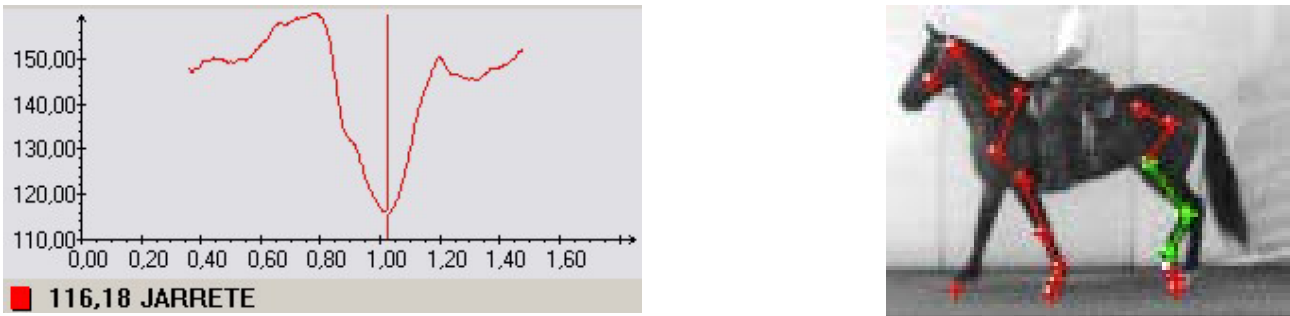

116,18 JARRETE

Figura 9. Curvas ângulo-tempo e ponto de máximo e mínimo do ângulo tibiotarsicometatársico (em verde). 


\section{REFERÊNCIAS BIBLIOGRÁFICAS}

BACK, W.; SHAMHARDT, H.C.; HARTMAN, $\mathrm{W}$. et al. A. Repetitive loading and oscillations in the distal fore and hind limb as predisposing factors for equine lameness. Am. J. Vet. Res., v.56, p.1522-1528, 1995

BACK, W.; SHAMHARDT, H.C.; BARNEVELD, A. Are kinematics of the walk related to the locomotion of a warmblood horse at a trot? Vet. Q., v.18, p.79-84, 1996.

BACK, W.; SHAMHARDT, H.C.; BARNEVELD, A. Kinematic comparison of the leading and trailing limb at the canter. Equine Vet. J., v.23, suppl., p.80-83, 1997.

BACK, W. Intra-limb coordination: Equine Locomotion. London: Saunders, 2001. p.95-134.

BARREY, E. Inter-limb coordination: Equine locomotion, London: Saunders, 2001. p.77-94.

CLAYTON, H.M. Comparison of the stride kinematics of the colected, working, medium and extended trot in horses. Equine Vet. J., v.26, p.230-234, 1994.

HUNT, W.F.; THOMAS, V.G.; STIEFEL, W. Analysis of video recorded images to determine linear and angular dimensions in the growing horse. Equine Vet. J. v.31, p.402-410, 1999.

LAGE, M.C.G.R. Caracterização morfométrica, dos aprumos e do padrão de deslocamento de eqüinos da raça Mangalarga Marchador e suas associações com a qualidade da marcha. 2001. 114f. Tese (Doutorado) - Escola de Veterinária, Universidade Federal de Minas Gerais, Belo Horizonte.

LEACH, D. H. A review of research on equine locomotion and biomechanics. Equine Vet. J., v.15, p.93-102, 1983.

MEERSHOEK, L.S.; VAN DE BOGERT, A.J. Mechanical Analysis of locomotion: Equine locomotion. London: Saunders, 2001. p.305-326.

MOTA, M. D. S. Conformação desempenho de eqüinos. Disponível em:

$<$ http://www.terravista.ciclone.com.br/ipanema/1 131/palescolina.htm > Acessado em: 25 out.1999.

RED LAKE - Disponível em: $<$ http://www.redlake.com> Acessado em: 12/06/2004.

SIMI- Simi - Motion Disponível em:< http:www.simi.com> Acessado em: 14/04/2004.

VAN WEEREN P.R.; VAN DE BOGERT A.J.;BARNEVELD A. Quantification of skin displacement near the carpal, tarsal and fetlock joints of the walking horse. Equine Vet. J., v.20, p.203-208, 1988.

VAN WEEREN, P.R.; VAN DE BOGERT, A.J.; BARNEVELD, A. Correction models for skin displacement in equine kinematic gait analysis. Equine Vet. Sci., v.12, p.178-192, 1992. 